\title{
APLICABILIDADE DA ARBITRAGEM NOS CONFLITOS TRABALHISTAS: DIÁLOGO, NEGOCIAÇÃO E CONSTRUÇÃO DO CONSENSO
}

\author{
Edilene Lôbo* \\ William Bruno de Castro Silva ${ }^{* *}$
}

\section{RESUMO}

Na sociedade repleta de litígios, pressionada pela ineficiência dos órgãos judiciais, destacamse técnicas alternativas para soluções desses conflitos, particularmente a arbitragem. O regramento próprio configura a autonomia da vontade que é a essência desse procedimento. Sob tal ângulo, este artigo examina sua aplicabilidade nos dissídios individuais e coletivos a cargo da Justiça do Trabalho. O objetivo é verificar a latitude da aplicação, orientado pelo método indutivo-prospectivo, examinando o estado da arte plasmado na jurisprudência e literatura, realçando sua importância na quadra atual de inibição de acesso à Justiça do trabalho pelo risco das penas pecuniárias previstas para o vencido.

Palavras-chave: Arbitragem; Conflitos Trabalhistas; Autonomia da Vontade; Construção do Diálogo; Acesso À Justiça.

\section{USE OS ARBITRATION IN LABOR DISPUTES: DIALOGUE, NEGOTIATIONS AND CONSENSUS BUILDING}

\begin{abstract}
In a society full of litigation, under pressure by Judiciary inefficiency, alternative techniques of dispute resolution stand out, especially arbitration. Its particular set of rules configures the autonomy of the will as the procedures essence. Under such light, this article examines its use in individual and collective labor disputes overseen by the Labor Justice. The aim is to examine the scope of the use, guided by the inductive-prospective method, inquiring the stateof-the-art shaped by jurisprudence and literature, highlighting its significance in the current state of access hindrance to Labor Justice by the risk of monetary penalties bestowed upon losing parties.
\end{abstract}

Key-words: arbitration; labor disputes; autonomy of will, dialogue building, access to justice.

\footnotetext{
*Doutora em Direito Processual (PUCMINAS). Mestre em Direito Administrativo (UFMG). Especialista em Processo Penal pela Universidad Castilla La Mancha (ES). Professora da Graduação e do Mestrado em Proteção de Direitos Fundamentais da Universidade de Itaúna. Professora Convidada da Pós-Graduação em Direito e Processo Eleitoral da PUCMINAS. Professora Convidada da Pós-Graduação em Direito Eleitoral do CEDIN. Coordenadora do Grupo de Pesquisa da Universidade de Itaúna: Processo Eleitoral Democrático: Inclusão e Visibilidade. Membro da Academia Brasileira de Direito Eleitoral ABRADEP. Advogada. Endereço: Rua Santa Catarina, $\mathrm{n}^{\circ}$ 1.627, cj. 1401, Bairro Lourdes, Belo Horizonte-MG, CEP 30.170-081. Email: edilenelobo@yahoo.com.br

** Mestrando do PPG em Proteção de Direitos Fundamentais da Universidade de Itaúna. Especialista em Processo do Trabalho (PUCMINAS). Professor da Graduação do Centro Universitário UNA. Advogado. Endereço: Avenida Simeao Ferreira de Souza, 775, Belvedere, Bom Despacho-MG, CEP:35519-000. Email: wbrunocastro@yahoo.com.br.
} 


\section{INTRODUÇÃO}

Hodiernamente muito se discute sobre a arbitragem e sua importância para a sociedade brasileira, na qual o litígio se encontra arraigado, impondo a busca por técnicas alternativas para solução de conflitos numa realidade em que o Poder Judiciário, diante dos poucos resultados que apresenta no desempenho de sua função tradicional, tornou-se moroso e caro.

O acesso à ordem jurídica, ampliando a compreensão do que se entende por acesso à justiça, para além, portanto, do aparato formal do Poder Judiciário, reconhecidamente em crise, como se adianta, é o lema para que os direitos fundamentais possam ser implementados, particularmente o que se coloca neste artigo: a proteção ao trabalho construída pelo diálogo e pela justa negociação nos conflitos que o envolvam.

No presente artigo, embora se vá tratar de tema específico, o que lhe orienta e justifica a abordagem, entretanto, serve para outras esferas, ou seja, a importância do acesso à justiça por meio de técnica própria, não judicial, destinada à solução de litígios de modo rápido, eficiente e seguro para os direitos fundamentais envolvidos. E para permitir aderência ao marco constitucional, a oferta que se faz é de superar as barreiras monetárias impostas por eventuais reformas desatentas à igualdade, buscando os aportes das novas tecnologias de comunicação para facilitarem o diálogo e a negociação - sem a ameaça de sanções descomunais aos vencidos ${ }^{1}$.

Como sabido, após a reforma trabalhista, houve a inclusão da arbitragem como técnica válida para a resolução de conflitos trabalhistas individuais, novidade condicionada a determinado piso salarial, conforme artigo 507-A da CLT ${ }^{2}$, excluindo os trabalhadores mais pobres, como se eles, pela mera condição econômica, não pudessem fruir da possibilidade de

\footnotetext{
1 Recentemente divulgou a BBC News Brasil em Londres, em reportagem de Laís Alegretti: "Sancionada há dois anos e em vigor desde novembro de 2017, a nova lei levou à diminuição na quantidade de processos apresentados à Justiça do Trabalho. O motivo, segundo especialistas, é que agora as pessoas correm o risco de ter de pagar custas e honorários se perderem a ação." (ALEGRETTI, Laís. Reforma trabalhista reduz processos e muda vida de advogados: 'Fonte secou'. Londres: BBC News Brasil, 08 jul. 2019. Disponível em: https://www.bbc.com/portuguese/brasil-48830450. Acesso em 28 ago. 2019.

${ }^{2}$ BRASIL. Lei no 13.467, de 13 de julho de 2017. Altera a Consolidação das Leis do Trabalho (...). Presidência da República. Brasília, DF, publicada no Diário da União de 14 de julho de 2017. Disponível em: https://www2.camara.leg.br/legin/fed/lei/2017/lei-13467-13-julho-2017-785204-norma-pl.html.Acesso: 19 jul. 2019. artigo 507-A: "Nos contratos individuais de trabalho cuja remuneração seja superior a duas vezes o limite máximo estabelecido para os benefícios do Regime Geral de Previdência Social, poderá ser pactuada cláusula compromissória de arbitragem, desde que por iniciativa do empregado ou mediante a sua concordância expressa, nos termos previstos na Lei n⿳⺈.9.307, de 23 de setembro de 1996.”
} 
solver conflitos por tal procedimento. Todavia, ao contrário do que a praxis mostra, justamente os mais pobres são os mais necessitados de solução justa e rápida, o que revela a antinomia normativa que se busca superar.

Desde a célebre decisão do Supremo Tribunal Federal reconhecendo constitucionalidade da então novel arbitragem, no Agravo Regimental na Sentença Estrangeira $n^{\circ}$ 5206-8, originária da Espanha, relatoria do Ministro Sepúlveda Pertence, esse procedimento orienta-se, basicamente, "no consentimento dos interessados e só pode ter por objeto a solução de conflitos sobre direitos disponíveis, ou seja, de direitos a respeito dos quais podem as partes transigir". 3

Embora esse julgado tratasse da arbitragem entre empresas como novidadoso no Brasil de então, se referindo à Lei n ${ }^{\circ}$ 9.307, que só chegou ao ordenamento nacional em 23 de setembro de 1996, a Constituição brasileira de 1988 já previa no $\S 1^{\circ}$ do artigo 114 , que nos dissídios coletivos, frustrada a negociação, seria possível "eleger árbitros"4.

A arbitragem na esfera trabalhista coletiva não é novidade, portanto, o que agora se estende aos dissídios individuais com a alteração legislativa registrada na polêmica reforma trabalhista recente, carecendo da necessária filtragem que se oferece ao longo deste artigo.

Para atingir seu objetivo, de colocar em foco a arbitragem nos dissídios individuais trabalhistas sem qualquer pedágio, mas garantindo que seja acessível, transparente, imparcial e pública, este trabalho inicia-se com os princípios básicos da disciplina para aferir compatibilidade com o procedimento defendido; prossegue abordando a lei da arbitragem e sua aplicação no campo de estudo combinando-a com a alteração propiciada pela reforma trabalhista; e chega ao resultado obtido oferecendo aplicação imediata.

\section{PRINCÍPIOS DA RELAÇÃO DE TRABALHO}

O direito do trabalho se informa por vários princípios, os quais têm função de estruturar o sistema juslaboral. Ao pensar em princípios remete-se a algum início, começo, ou

\footnotetext{
${ }^{3}$ BRASIL. Supremo Tribunal Federal. Agravo Regimental na Sentença Estrangeira n ${ }^{\circ}$ 5206-8. Relator Ministro Sepúlveda Pertence. Julgamento de 12/12/2001, publicado em Brasília, CF, no Diário da Justiça de 30/04/2004, p. 59. Disponível em: http://redir.stf.jus.br/paginadorpub/paginador.jsp?docTP=AC\&docID=345889 Acesso em 28 ago. 2019.

${ }^{4}$ BRASIL. Constituição da República Federativa do Brasil de 1988. Brasília, DF. Publicada no Diário Oficial da União de 05 out. 1988. Disponível em: http://www.planalto.gov.br/ccivil_03/Constituicao/Constitu icao.htm. Acesso em: 16 jul. 2019.
} 
ponto de partida, conforme a tradução literal da palavra aponta. Para Norberto Bobbio, entretanto, os princípios superam a própria lei, utilizados como diretrizes de interpretação, mais amplos e completos. (BOBBIO, 1995, p. 155-164)

Carlos Henrique Bezerra leite ao analisar a obra de Norberto Bobbio descreve que os princípios são divididos em gerais e específicos, estes em concordância com aqueles, embasando o ordenamento, como dito. Declina ainda que os princípios podem ser expressos ou não, encontrados nos diplomas normativos variados ou evidenciados por abstração da norma, isto é, interpretação adequada.

Os princípios gerais são os comuns a todo o ordenamento, mas para o presente estudo, a dignidade da pessoa humana é o principal. Já os princípios específicos são ligados diretamente à matéria invocada, como, por exemplo, o da proteção e o da continuidade do contrato de trabalho. (LEITE, 2016, p.72/73)

Maurício Godinho Delgado tem mesmo entendimento:

Insistimos que tais princípios formam o núcleo justrabalhista basilar, por, a um só tempo, não apenas incorporarem a essência da função teleológica do Direito do Trabalho, como por possuírem abrangência ampliada e generalizante ao conjunto desse ramo jurídico, tudo isso sem que se confrontem de maneira inconciliável com importantes princípios jurídicos gerais, externos ao ramo jurídico especializado. (DELGADO, 2015, p.200/2001)

Desse modo, abordam-se tais princípios para, ao final, apontar a compatibilidade do procedimento heterocompositivo da arbitragem nas relações de trabalho, apto, portanto a solucionar lides de forma eficiente, segura e capaz de ofertar o bem da vida buscado.

\subsection{Princípio da dignidade da pessoa humana}

O princípio da dignidade da pessoa humana é um dos mais importantes fundamentos existentes na ordem jurídica brasileira, tipificado no artigo $1^{\circ}$, inciso III, da Constituição. A par de sua supremacia, todas as normas jurídicas lhe devem base, sob risco de inconstitucionalidade. Tamanha sua importância, desde 1948, nomeadamente na Declaração Universal de Direitos Humanos - DUDH, é expresso de modo indelével que: "Artigo $1^{\text {o }}$ Todos 
os seres humanos nascem livres e iguais em dignidade e em direitos. Dotados de razão e de consciência, devem agir uns para com os outros em espírito de fraternidade."

André Gustavo Correia Andrade leciona a respeito desse estruturador da vida social fraterna, como quer a DUDH:

\begin{abstract}
A dignidade é composta por um conjunto de direitos existenciais compartilhados por todos os homens [e mulheres], em igual proporção. Partindo dessa premissa, contesta-se aqui toda e qualquer idéia de que a dignidade humana encontre seu fundamento na autonomia da vontade. A titularidade dos direitos existenciais, porque decorre da própria condição humana, independe até da capacidade da pessoa de se relacionar, expressar, comunicar, criar, sentir. (ANDRADE, 2003, p. 317)
\end{abstract}

Nessa mesma extensão, a aludida Declaração Universal de Direitos Humanos já descrevia o que era o trabalho digno, apontando quatro condições elementares para seu desempenho, como se lê no artigo $23^{\circ}$ :

1. Toda a pessoa tem direito ao trabalho, à livre escolha do trabalho, a condições equitativas e satisfatórias de trabalho e à proteção contra o desemprego.

2.Todos têm direito, sem discriminação alguma, a salário igual por trabalho igual.

3.Quem trabalha tem direito a uma remuneração equitativa e satisfatória, que lhe permita e à sua família uma existência conforme com a dignidade humana, e completada, se possível, por todos os outros meios de proteção social.

4.Toda a pessoa tem o direito de fundar com outras pessoas sindicatos e de se filiar em sindicatos para defesa dos seus interesses. ${ }^{6}$

Complementando, o art. $24^{\circ}$ da DUDH dispõe sobre repouso, jornada e lazer: "Toda a pessoa tem direito ao repouso e aos lazeres, especialmente, a uma limitação razoável da duração do trabalho e as férias periódicas pagas.",

Junto à dignidade do trabalho vem a proteção ao meio ambiente do trabalho, visto que não existe melhor forma de dignificá-lo do que proteger o trabalhador. Isto é, garantir um meio ambiente saudável evitando acidentes e/ou doenças ocupacionais.

\footnotetext{
${ }^{5}$ ONU. Organização das Nações Unidas. Escritório do Alto Comissariado. Declaração Universal dos Direitos Humanos. $\quad$ Paris: 10 dez. $1948 . \quad$ Disponível em: http://www.ohchr.org/EN/UDHR/Documents/UDHR_Translations/por.pdf. Acesso em: 16.jun.2019.

${ }^{6}$ ONU. Organização das Nações Unidas. Escritório do Alto Comissariado. Declaração Universal dos Direitos Humanos. $\quad$ Paris: 10 dez. $1948 . \quad$ Disponível http://www.ohchr.org/EN/UDHR/Documents/UDHR_Translations/por.pdf. Acesso em: 16.jun.2019.

${ }^{7}$ ONU. Organização das Nações Unidas. Escritório do Alto Comissariado. Declaração Universal dos Direitos $\begin{array}{llllll}\text { Humanos. } & \text { Paris: } & 10 & \text { dez. } & \text { em: }\end{array}$ http://www.ohchr.org/EN/UDHR/Documents/UDHR_Translations/por.pdf. Acesso em: 16.jun.2019.
} 
É nesse traçado de dignidade que vêm as garantias estampadas no artigo $7^{\circ}$ da Constituição, designando o que é trabalho valorizado e adequado, especialmente realçando os preceitos da redução dos riscos, adotando-se "normas de saúde, higiene e segurança". ${ }^{8}$

Assim, devem-se resguardar os direitos inerentes ao trabalho, primeiramente com o intuito de proteger a dignidade do trabalhador por meio da irredutibilidade do salário, jornada adequada, sem labor extraordinário além do previsto legalmente, condições salubres e protegidas pelo uso de equipamentos obrigatórios, convívio social, dentre tantos outros. Sendo estes preceitos de dignidade indispensáveis à interpretação de qualquer lei que vise alterar disposições trabalhistas, vale esmiuçar o que dispõe o próximo princípio estudado.

\subsection{Princípio da valorização do trabalho}

O princípio da valorização do trabalho também é previsto na Constituição da República em pelo menos dois artigos: no $1^{\circ}$, inciso IV, e 170, inciso VIII. Ambos descrevem claramente a devoção do sistema ao trabalho humano digno e capaz de oportunizar a produção de riquezas com o pleno emprego.

Nesse viés, é de se repetir que a valorização do trabalho é princípio fundamental e pilar da ordem econômica. Logo, devem ser envidados todos os esforços para sua proteção.

Bem por isso a ordem econômica resguarda o direito ao emprego pleno, entendido como trabalho que traga conforto ao trabalhador, que supra suas necessidades econômicas e propicie inclusão social.

Daí vislumbra-se, ao lado do trabalho pleno e dos seus valores sociais, a livre iniciativa, que fomenta a relação capital-trabalho, devendo ser harmonizadas para não invalidar o fundamento.

Victor Hugo Nazário Stuchi, citando Leonardo Bocorny, discorre sobre a valorização do trabalho humano destacando o papel do trabalhador como agente de transformação social:

\footnotetext{
A valorização do trabalho humano, esclareça-se, não somente importa em criar medidas de proteção ao trabalhador, como foi destacado nos Estados Sociais. [...],o grande avanço do significado do conceito que se deu no último século foi no sentido de se admitir o trabalho (e o trabalhador) como principal agente de transformação da economia e meio de inserção social, por isso, não pode ser excluído do debate

${ }^{8}$ BRASIL. Constituição da República Federativa do Brasil de 1988. Brasília, DF. Publicada no Diário Oficial da União de 05 out. 1988. Disponível em: http://www.planalto.gov.br/ccivil_03/Constituicao/Constitu icao.htm. Acesso em: 16 jul. 2019.
} 
relativo às mudanças das estruturas de uma sociedade. Assim, o capital deixa de ser o centro dos estudos econômicos, devendo voltar-se para o aspecto, talvez subjetivo, da força produtiva humana. (STUCHI, 2018, p. 135)

Nota-se que a proteção do trabalho digno é essencial para a livre iniciativa como garante do desenvolvimento social. Não há falar em sobreposição, mas em harmonização de preceitos.

A propósito dessa harmonização, indagação crucial é colocada quando se fala do trabalho em plena precarização gerada pelas plataformas digitais, porque é essencial proteger condições mínimas de trabalhado na era do capitalismo de plataformas. ${ }^{9}$

\subsection{Principio da proteção}

O princípio da proteção talvez seja o que tem mais importância no cenário laboral, bem visto seu sentido axiológico. O intuito é dar equilíbrio à combinação capital e trabalho, estipulando assim, bases mínimas para a relação trabalhista.

O princípio da proteção pode ser visto mesmo como macro princípio que se desdobra em três outros, quais sejam: in dubio pro operário, aplicação da norma mais favorável e adoção da condição mais benéfica. Todos eles dirigidos à proteção do trabalhador contra as arbitrariedades do mercado.

Segundo Carlos Henrique Bezerra Leite o princípio in dubio pro operário consiste na compreensão da existência de possibilidades de várias interpretações a uma só regra, sendo a correta aquela que favoreça o empregado, parte hipossuficiente da relação. Em que pese à

\footnotetext{
${ }^{9}$ BOLZAN DE MORAIS explica o novo formato: "Esta é uma marca que não se tem como afastar do Estado (Liberal) Social, onde o liberismo contamina o seu arranjo político, funcionando, acima de tudo, como sustentáculo/anteparo para a economia capitalista. Portanto, o ideal do Estado (Liberal) Social parece de difícil realização, se não impossível, ante esta tensão intransponível entre os interesses do capital e os anseios das classes populares, em maior ou menor grau. Isso se reforça em um contexto de transformação deste arranjo primário com a mutação do "velho" capitalismo de produção para o novo capitalismo financeiro, mais ainda, talvez, para um capitalismo flexível da economia colaborativa - um "capitalismo de plataformas" -, onde o princípio da solidariedade que embasa esta adjetivação do Estado perde suas referências. Esta estratégia não parece estar conforme com o modelo de Estado (Liberal) Social, que indica aceitar - e aceita - que o ideal prático que lhe compõe os limites é o de assegurar ao maior número "possível" o acesso à direitos, tendo consciência de que nesta contabilidade muitos, ainda, ficam "de fora". Dito de outra forma, no interior do marco do Estado (Liberal) de Direito, mesmo como Estado (Liberal) Democrático de Direito, não cabe nada além daquilo que ele mesmo comporta, tanto mais, ainda, quando as práticas do (neo)liber(al)ismo acabam por submeter as funções sociais do Estado ao cálculo econômico, introduzindo critérios de rentabilidade nos serviços públicos, como alerta Z. Bauman, ou quando seus resultados são medidos a partir da substituição do modelo de pleno emprego pelo da eficiência econômica e pelo equilíbrio das contas públicas, como aponta A. Nunes. (BOLZAN DE MORAIS, José Luís. O Estado de direito "confrontado" pela "revolução da internet"!. Revista Eletrônica do Curso de Direito da Universidade Federal de Santa Maria. V. 13, n. 3/2018, p. 881-882)
} 
norma mais benéfica, o autor exemplifica que mesmo diante de um regulamento empresarial este só poderá ser revogado quando sobrevier outro melhor, que beneficie o trabalhador, podendo, ainda, o obreiro, escolher livremente qual será aplicado. (LEITE, 2016, p.82/89)

Mauricio Godinho Delgado segue mesma direção:

O princípio tutela influi em todos os segmentos do Direito Individual do Trabalho,
influindo na própria perspectiva desse ramo ao construir-se, desenvolver-se e atuar
como direito. Efetivamente, há ampla predominância nesse ramo jurídico
especializado de regras essencialmente protetivas, tutelares da vontade e interesses
obreiros; seus princípios são fundamentalmente favoráveis ao trabalhador; suas
presunções são elaboradas em vista do alcance da mesma vantagem jurídica
retificadora da diferenciação social prática. (DELGADO, 2015, p.201)

Certamente que tais autores tratam da relação típica de emprego porque quando o assunto envolve a prestação remota, por meio das plataformas digitais, até a geografia desaparece, que dirá regulação e proteção formais.

É importante conhecer a categorização das plataformas digitais para reflexão futura acerca da proteção deste tipo de trabalho. Embora não seja foco deste trabalho, é essencial para o estudioso do direito do trabalho, conhecer a descrição elementar da OIT acerca dos tipos: 


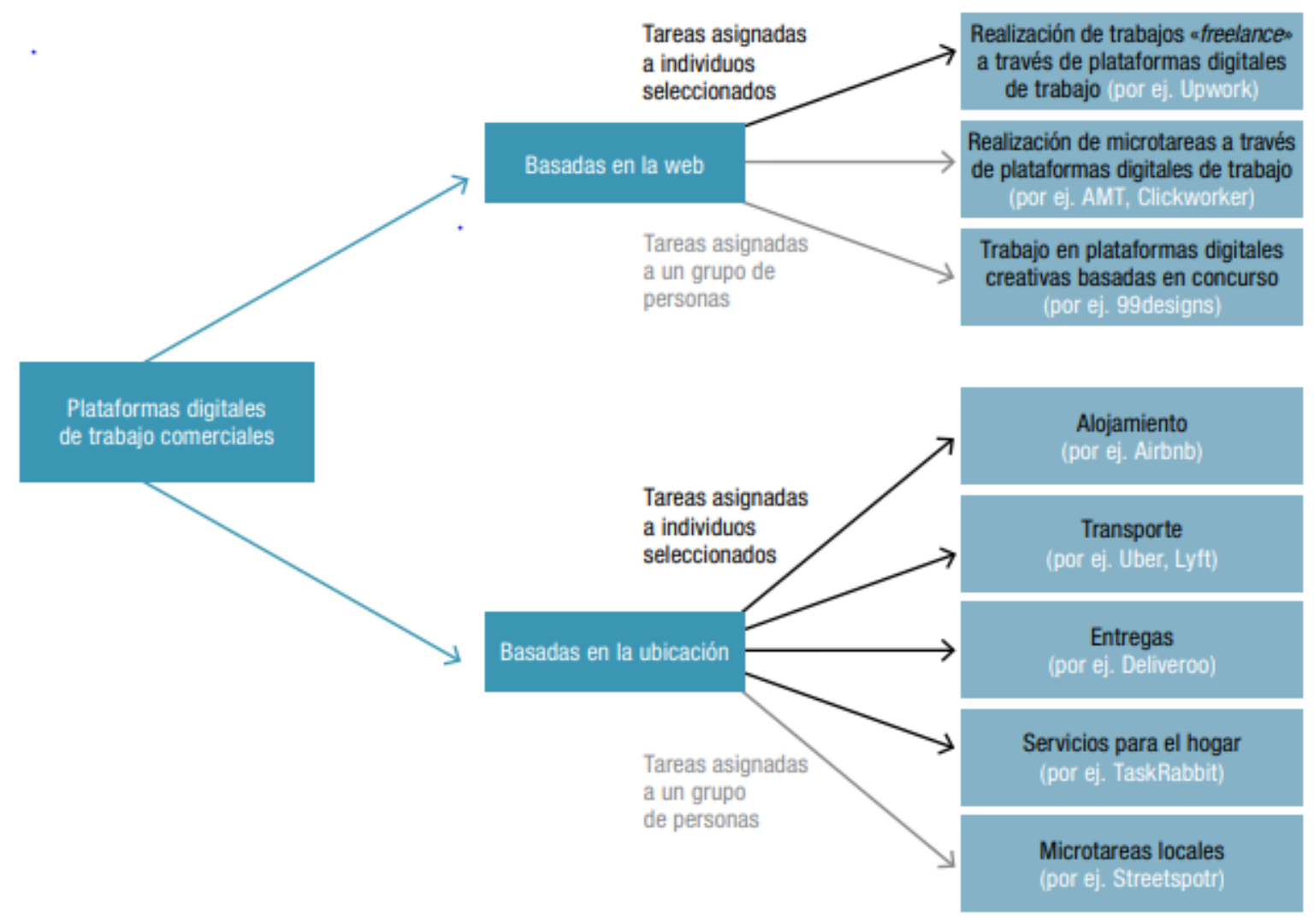

Não se duvida, em mera observação da realidade, que:

Muitos trabalhadores das plataformas digitais vivem situação econômica precária. Uma em cada cinco pessoas vive em casa cujo salário mensal não é suficiente para cobrir as necessidades básicas. Essa proporção é especialmente alta entre os trabalhadores de plataformas digitais da África (42\%), da Ásia e Pacífico (24\%), e da América Latina (23\%), embora menor, ainda que significativa, na América do Norte e na Europa e Ásia Central (em torno de 17\%). Uma porcentagem maior de pesquisados $(42 \%)$ vive em famílias que não tem poupança de emergência que equivalha a um mês de salário. Ademais, em torno de $44 \%$ têm dívidas como, por exemplo, as contraídas por empréstimos estudantis, financiamento de automóveis, gastos médicos ou jurídicos, ou empréstimos de parentes (sem contar os empréstimos hipotecários). A porcentagem de famílias com dívidas é maior na América do Norte $(58 \%)$, do que na América Latina $(33 \%)$ e na Europa e Ásia Central $(36 \%){ }^{11}$

\footnotetext{
${ }^{10}$ OIT. Oficina Internacional del Trabajo. Las plataformas digitales y el futuro del trabalho: Cómo fomentar el trabajo decente en el mundo digital. $1^{\mathrm{a}}$ ed. Genebra: 2019, p. 5.

${ }^{11}$ No original: "Muchos trabajadores de las plataformas digitales viven una situación económica precaria. Una de cada cinco personas vive en un hogar cuyo ingreso mensual no es suficiente para cubrir las necesidades básicas. Esta proporción es especialmente alta entre los trabajadores de plataformas digitales de África (42 por ciento), de Asia y el Pacífico (24 por ciento), y de América Latina (23 por ciento), mientras que es menor, aunque igualmente significativa, en América del Norte y en Europa y Asia Central (alrededor del 17 por ciento). Un porcentaje mayor de encuestados (42 por ciento) vive en hogares que no tienen suficiente dinero ahorrado para cubrir una emergencia que equivalga a los ingresos de un mes. Además, alrededor del 44 por ciento de los
} 
O subemprego que as plataformas propiciam é outro problema para a proteção do trabalho no mundo digital. Nesse cenário, o princípio da continuidade da relação de emprego, para garantir segurança jurídica, se torna crucial. Nessa quadra, é bastante importante a adoção de procedimento rápido e seguro que possa viabilizá-lo.

\title{
1.4. Princípio da continuidade da relação de emprego
}

O princípio da continuidade da relação de emprego preceitua que o contrato de trabalho deve ser preservado para propiciar segurança jurídica e incorporar os trabalhadores ao mecanismo empresarial. Nesses moldes, é como escreve Alice Monteiro de Barros:

Outro princípio é o da continuidade, que visa à preservação do emprego com o
objetivo de dar segurança econômica ao trabalhador e incorporá-lo ao organismo
empresarial. Para entender esse princípio, cumpre ressaltar que uma característica do
contrato de trabalho é o trato sucessivo, ou seja, ele não se esgota mediante a
realização instantânea de certo ato, mas perdura no tempo. Daí se infere que a
relação de emprego pressupõe uma vinculação que se prolonga. (BARROS, 2011,
p.146/147)

Tal princípio encontra guarida no texto constitucional, especificamente no artigo $7^{\circ}$, inciso I, que prevê a proteção do trabalhador por dispensa arbitrária, a despeito de ainda não ter havido regulamentação infraconstitucional adequada nesse sentido, como anota BARROS (2011, p.146).

Na problemática da manutenção do emprego em tempos de virtualização do mundo do trabalho, o que se tem é a busca incessante por um mínimo de remuneração, ainda que à custa de mais trabalho e cada vez menos segurança. É o que registram pesquisas recentes:

\begin{abstract}
A falta de uma relação laboral clara produz impacto sobre a regularidade do trabalho. Muitas vezes, os trabalhadores das plataformas digitais não encontram trabalho suficiente e muitos têm que busca-lo de forma contínua sem que haja garantia de que vai encontrar. Isso contrasta claramente com o "trabalho em casa" tradicional de baixa qualificação na indústria manufatureira, no qual os
\end{abstract}

hogares tienen deudas como, por ejemplo, las contraídas por préstamos estudiantiles, cuotas por la compra de un automóvil, gastos médicos o jurídicos, o préstamos de parientes (sin contar los préstamos hipotecarios). El porcentaje de hogares con deudas es más alto en América del Norte (58 por ciento) que en América Latina (33 por ciento) y en Europa y Asia Central (36 por ciento) (gráfico 4.5).” (OIT. Oficina Internacional del Trabajo. Las plataformas digitales y el futuro del trabalho: Cómo fomentar el trabajo decente en el mundo digital. $1^{\mathrm{a}}$ ed. Genebra: 2019, p. 55.) 
trabalhadores tinham habitualmente um fluxo regular de trabalho procedente do empregador que oferecia trabalho de forma regular. $\mathrm{O}$ desejo de buscar mais trabalho se deve, em parte, à remuneração insuficiente, e as conclusões a que chega a pesquisa da OIT indica que uma esmagadora maioria dos participantes (88\%) respondeu, em 2017, que gostariam de ter mais trabalho (gráfico 4.6). Em média, essas pessoas queriam ter 11,6 horas a mais de trabalho por semana nas plataformas digitais. Essas conclusões são muito similares às de 2015. O desejo de ter mais trabalho nas plataformas digitais era similar para homens $(86 \%)$ e mulheres $(90 \%){ }^{12}$

Assim, se o ordenamento jurídico preconiza a manutenção do contrato de trabalho e se constata sua precarização cada vez mais, particularmente no mundo virtual de relações fluidas e nem sempre claras das plataformas digitais, remarcadas pela ausência de regulação, vale lançar mão da arbitragem como procedimento apto a garantir mínimo de direitos nas relações individuais do trabalho. É importante o uso da linguagem virtual, inclusive, nesse procedimento, considerando a possibilidade da adoção da arbitragem por meio eletrônico, tal qual já se vem fazendo com o processo judicial eletrônico.

À luz de tais considerações, passa-se a explorar conceitos iniciais sobre o procedimento destacado, bem desenhada na legislação.

\section{ELEMENTOS INICIAIS SOBRE ARBITRAGEM}

Quando da transposição da justiça privada para a justiça pública, o Estado se fez encarregado de resolver os conflitos, chamando para si o monopólio de solver demandas por meio do processo formal, a cargo dos juízes. Dessa forma, superada a autotutela pelo risco de abusos, o Estado tomou o monopólio da judicação, assumindo dever de julgar litígios. ${ }^{13}$

\footnotetext{
${ }^{12}$ No original: "La falta de una relación laboral clara produce un impacto sobre la regularidad del trabajo. Muchas veces, los trabajadores de las plataformas digitales no encuentran trabajo suficiente y tienen que buscarlo en forma continua sin que eso sea garantía de que vayan a encontrarlo. Esto contrasta claramente con el "trabajo en casa" tradicional de baja calificación en la industria manufacturera, en el que los trabajadores tenían habitualmente un flujo regular de trabajo procedente del proveedor o del contratista que les proveía de trabajo en forma regular. El deseo de buscar más trabajo se debe, en parte, a que la paga es insuficiente, y las conclusiones a las que llega la encuesta de la OIT indican que una abrumadora mayoría de los participantes (un 88 por ciento) respondió, en 2017, que le gustaría tener más trabajo (gráfico 4.6). En promedio, estas personas querían tener unas 11,6 horas más de trabajo por semana en las plataformas digitales. Estas conclusiones son muy similares a las de 2015. El deseo de tener más trabajo en las plataformas digitales era similar para hombres (86 por ciento) y mujeres (90 por ciento)." (OIT. Oficina Internacional del Trabajo. Las plataformas digitales y el futuro del trabalho: Cómo fomentar el trabajo decente en el mundo digital. $1^{\mathrm{a}}$ ed. Genebra: 2019, p. 66).

${ }^{13}$ Como desenhado por Rosemiro Pereira Leal na sua importante obra sobre teoria geral do processo:

" 5 = Jurisdição $\rightarrow$ a partir do momento em que o Estado assumiu uma posição de independência, passando a exercer um poder mais acentuado de controle social. Surge primitivamente pela atividade do julgador, constituindo monopólio estatal de arbitrar o direito. O pretor romano tinha jurisdição e ditava os procedimentos a seu modo para resolver os litígios.
} 
Contudo, a arbitragem antecede esse período, reportado inicialmente à Grécia antiga e a Roma, onde tal instituto já era utilizado para os conflitos privados.

José Luiz Bolzan de Morais trata das origens da arbitragem na primeira edição de sua obra mater ${ }^{14}$, como se lê:

Ao tratar, especificamente, da arbitragem como estratégia de tratamento de controvérsias é importante recuperar suas origens junto ao processo civil romano da época pré-clássica e clássica, denominado ordo iudiciorum privatorum. O árbitro moderno é figura análoga ao juiz privado romano (iudex) e o compromisso arbitral a atual roupagem da litis contestatio. No período arcaico o Estado Romano não interferia no tratamento.

No período arcaico o Estado Romano não interferia no tratamento de litígios deixando que os particulares se incumbissem de solucionar as controvérsias surgidas da sua vida quotidiana. Posteriormente o Estado tratou de regular e controlar o método privado de tratamento de litígios, terminando por assumi-lo totalmente. Assim, é necessário dizer que a raiz do direito processual romano é eminentemente privada (ordo iudiciorum privatorum) tendo evoluído progressivamente para a estrutura estatal (cognitio extra ordinem). Percorrendo o histórico da arbitragem, percebe-se que o mesmo se evidenciou desde a Antiguidade e daí em diante passou a assumir papel importante no tratamento de conflitos. Encontram-se provas de arbitragens entre os povos gregos, tanto entre particulares como entre cidadesestados, este último podendo ser exemplificado pelo Tratado de Paz traçado entre Esparta e Atenas, em 445 a. C. Tradicional também é entre os romanos, que a empregavam largamente nas relações particulares. (BOLZAN DE MORAIS, 2012, pag. 117/118)

Carlos Alberto Carmona, em corroboração, define arbitragem como "especial modalidade alternativa de resolução de controvérsias sobre direitos disponíveis, através da qual as partes escolhem um juiz privado para decidir o conflito, de forma autoritativa, ou seja, vinculativa para os litigantes." (CARMONA, 1999, p. 421)

Insta aclarar que a arbitragem é técnica que se resolve por meio do procedimento alternativo, sendo faculdade das partes para efetivação do direito em discussão.

José Luiz Bolzan de Morais registra, ainda:

$6=$ Processo $\rightarrow$ surgiu na modernidade para criar e balizar a jurisdição e conter a vontade do julgador. Os comandos da jurisdição são estabelecidos pelo PROCESSO: define-se por uma principiologia que se destina a criar e disciplinar os procedimentos de resolução das controvérsias. Com a evolucionariedade do direito e, principalmente, do PROCESSO, não precisamos mais nos louvar na herança do passado. Urge que depuremos formas arcaicas de entender o direito, fazendo uma filtragem dos conceitos para nos livrar das amarras do direito romano." (LEAL, Rosemiro Pereira. Teoria Geral do Processo: primeiros estudos. $14^{\mathrm{a}}$ ed. Belo Horizonte: Fórum, 2018, p. 391/392).

${ }^{14}$ Quando o fechamento deste trabalho se encontrava em $3^{\text {a }}$ edição revista e atualizada, em co-autoria, no prelo, a repaginação da obra aqui citada. Razão pela qual não se lança mão de seus acréscimos mais atualizados, embora para o fim do presente trabalho, sabe-se de pouca alteração, valendo, ainda, as transcrições feitas. 


\begin{abstract}
Assim, a arbitragem aparece como uma estratégia de extrema importância, pois, como se verá, o Estado confere à mesma algumas "faculdades jurisdicionais", como outorgar às decisões arbitrais força de coisa julgada, sem a necessidade de homologação das mesmas pelos tribunais estatais.

Nestes termos, arbitragem é o meio pelo qual o Estado, "em vez de interferir diretamente nos conflitos de interesses, solucionando-os com a força da sua autoridade, permite que uma terceira pessoa o faça, segundo determinado procedimento e observado um mínimo de regras legais, mediante uma decisão com autoridade idêntica à de uma sentença judicial". Assim, as partes, ao fazerem a opção pela justiça arbitral, afastam a jurisdição estatal substituindo-a por outra estratégia de tratamento de conflitos, reconhecida e regulada pelo Estado de modo que permite a execução das decisões ali proferidas bem como a anular das decisões que não observarem um mínimo de regras exigidas pelo legislador. (BOLZAN DE MORAIS, 2012, pag. 120/121)
\end{abstract}

A arbitragem é aplicável no ordenamento brasileiro a partir da Lei ${ }^{\circ}$ 9.307/1996, atualizada pela Lei n 13.129/2015, cujo procedimento, genericamente permite que:

$1^{\circ}$ ) se possa estipular a arbitragem como forma de resolução do conflito em caso de direito disponível;

$2^{\circ}$ ) o árbitro pode ser livremente escolhido assim como se estipular prazo para prolação da sentença, que se limitará a 06 meses, quando inexistir um previamente fixado;

$3^{\circ}$ ) a sentença arbitral produzirá os mesmos efeitos de sentença judicial, inclusive se constituindo título executivo;

$4^{\circ}$ ) a nulidade da sentença arbitral pode ser pleiteada em procedimento judicial, observando o prazo legal de 90 dias após a notificação da respectiva sentença;

$5^{\circ}$ ) na ausência de cumprimento espontâneo, poderá haver busca do adimplemento da sentença arbitral no procedimento judicial.

Sendo assim, a arbitragem mostra-se conveniente eis que é procedimento seguro de resolução de conflitos, possuindo celeridade e constituindo um título executivo que pode ser executado por meios variados, contudo pouco utilizado nas relações econômicas tradicionais, embora existente no direito coletivo do trabalho há bastante tempo, como se anotou no preâmbulo deste ensaio.

\title{
2.1. Aplicabilidade da arbitragem no direito coletivo e no direito individual do trabalho
}

Já se disse em linhas volvidas que a arbitragem no direito coletivo do trabalho é matéria constitucional, claramente estampada no artigo $114, \S \S 1^{\circ}$ e $2^{\circ}$, do Texto Maior. Todavia, só com a edição da Lei $n^{\circ} 13.467 / 2017$, que passou a haver lei expressa prevendo 
sua possibilidade às lides individuais. Superando eventual inconstitucionalidade da previsão por meio de lei ordinária (já que matéria se encontrou originariamente regulada na Constituição, dando conta de seu alto grau de fundamentalidade para a coletividade) ${ }^{15}$, a arbitragem pode ser adotada na esfera individual, porém a superar o limite em decorrência do salário do empregado, como se lê no artigo 507-A da CLT. ${ }^{16}$

Malgrado essa distinção, a se admitir que a regra escrita pudesse se alhear do princípio da igualdade, estruturador do Estado Democrático de Direito, pelo qual descabe impor discriminação para desqualificar o cidadão, vale examinar com mais atenção a lei em tela para registrar a aplicabilidade irrestrita do procedimento, com a filtragem que se indica a seguir.

\subsection{Igualdade e aplicabilidade da arbitragem}

Remarque-se que a arbitragem paira sobre a parte disponível dos direitos trabalhistas, lembrando que há distinção necessária acerca do que comporta negociação, para ver, aquela absoluta. Entende-se por direito absoluto, portanto inegociável, quando se tratar de questões envolvendo a saúde e a segurança do trabalho, por exemplo.

Todavia, quanto ao que envolve o pagamento dos salários, os valores das horas extraordinárias, dentre outros tangíveis e quantificáveis, tal indisponibilidade mostra-se relativa, pois podem ser alvo de transação.

Ademais, entende-se que após o termino do contrato de trabalho as partes podem confeccionar qualquer acordo e valerem-se da via que acharem necessária, sendo possível a arbitragem, por evidente. E nem se diga da afixação de eventual obstáculo, considerando a condição econômica dos empregados envolvidos, porque o objetivo constitucional é vedar a discriminação, por quaisquer meios. Dessa moda, sem que se justifique a razão de fixar

\footnotetext{
${ }^{15}$ Tramita no STF a ADI n ${ }^{\circ}$ 5766, de relatoria do Ministro Luís Roberto Barroso, manejada pela Procuradoria Geral da República, questionando a imposição de custas aso vencidos, obstáculo insuperável ao acesso à justiça na via pública. Disponível em: http://portal.stf.jus.br/processos/detalhe.asp?incidente=5250582. Acesso: 28 ago. 2019.

${ }^{16}$ BRASIL. Lei no 13.467, de 13 de julho de 2017. Altera a Consolidação das Leis do Trabalho (...). Presidência da República. Brasília, DF, publicada no Diário da União de 14 de julho de 2017. Disponível em: https://www2.camara.leg.br/legin/fed/lei/2017/lei-13467-13-julho-2017-785204-norma-pl.html.Acesso: 19 jul. 2019. Artigo 507-A: "Nos contratos individuais de trabalho cuja remuneração seja superior a duas vezes o limite máximo estabelecido para os benefícios do Regime Geral de Previdência Social, poderá ser pactuada cláusula compromissória de arbitragem, desde que por iniciativa do empregado ou mediante a sua concordância expressa, nos termos previstos na Lei n⿳⺈.9.307, de 23 de setembro de 1996.”
} 
pedágio envolvendo a remuneração do empregado, filtrando o dispositivo pelo artigo $3^{\circ}$, IV e artigo $5^{\circ}$, caput, da Constituição, é possível que se aplique a arbitragem independente do valor da remuneração.

Por outro lado, Guilherme Rizzo Amaral sugere a adoção de quatro providências para que a arbitragem trabalhista individual se faça de forma segura e profícua. São elas:

a) "exigência de que procedimentos arbitrais sejam necessariamente administrados por instituições", para evitar a escolha de mesmos árbitros "sem a intermediação de câmaras arbitrais ou instituições similares". Essa providência fomentaria o equilíbrio e evitaria inclinações parciais; (AMARAL, online, 2018)

b) "desvinculação das instituições arbitrais a órgãos de classe, sejam eles patronais ou de empregados", para privilegiar, outra vez, a imparcialidade; (AMARAL, online, 2018)

c) "publicidade do procedimento arbitral" porque a confidencialidade, que se aplica sos procedimentos envolvendo interesses comerciais, "não permite uma avaliação completa do funcionamento da arbitragem trabalhista" e "acabará alimentando a neofobia, desconfiança que sempre acompanha a adoção de novos institutos jurídicos”; (AMARAL, online, 2018)

d) "a arbitragem trabalhista deverá necessariamente ser de direito" porque aquela por equidade ("pela qual o árbitro pode decidir com base no seu senso de justiça") pode estimular o desrespeito à lei, podendo prejudicar o trabalhador. (AMARAL, online, 2018)

Acrescente-se a tais providências, a que garanta a assistência do advogado aos trabalhadores pobres, assim como que não se lhes sejam cobradas quaisquer custas, instituindo-se a arbitragem trabalhista gratuita, tal qual faz a Espanha com a arbitragem gratuita de consumo ${ }^{17}$, que deve ser, inclusive, apoiada por órgãos governamentais.

Voltando à realidade brasileira, o Tribunal Superior do Trabalho, aliás, vem entendendo a aplicabilidade da lei de arbitragem a diversos dissídios individuais, envolvendo mão-de-obra portuária regida pela Lei $\mathrm{n}^{\circ} 12.815 / 2013$, não só para tratar do término da relação de emprego. Tome-se como importante precedente o seguinte:

AGRAVO EM AGRAVO DE INSTRUMENTO. ARBITRAGEM. CONFLITO INDIVIDUAL. PORTUÁRIO. ESCOLHA DO MINISTÉRIO PÚBLICO DO TRABALHO COMO ÁRBITRO, PELOS SINDICATOS. A sentença arbitral

\footnotetext{
${ }^{17}$ ESPANHA. Decreto Real no 231/2008, de 15 de fevereiro, publicado no BOE-A-2008-357, de 25 de fevereiro de 2018, disponível em:

http://www.madrid.org/cs/Satellite?c=FRAME_Contenido_FA\&childpagename=PortalConsumidor\%2FFRAME _Contenido_FA\%2FPTCS_contenidoReportajes\&cid $=1343066136568 \& \mathrm{p}=1343064181510 \&$ pagename $=$ PTCS_ wrapper. Acesso em 29 ago. 2019.
} 
decidiu pela suspensão do autor por trinta dias, em razão de sua ausência injustificada do trabalho por 60 dias. A jurisprudência desta c. Corte se inclina para a impossibilidade da utilização da arbitragem para solução de conflitos individuais, em razão da hipossuficiência econômica do empregado. Entretanto, o caso dos autos possui peculiaridades que afastam a aplicação desse entendimento. Primeiramente, a própria Lei dos Portos (Lei $\mathrm{n}^{\circ}$ 12.815/2013, art. 37) permite a utilização da arbitragem quando há impasse no âmbito da comissão paritária. Ora, se a própria legislação prevê a possibilidade da utilização da arbitragem em dissídio individual específico, no caso, do trabalhador portuário e para as hipóteses delimitadas na própria lei, não há falar em impossibilidade de utilização da arbitragem para a controvérsia dos autos. Ressalte-se que não há controvérsia quanto ao árbitro escolhido, mas sim quanto a quem o escolheu. Por certo que o Ministério Público do Trabalho poderia atuar como árbitro, pois além de ter por atribuição institucional "atuar como árbitro, se assim for solicitado pelas partes, nos dissídios de competência da Justiça do Trabalho" (art. 83, XI, da LOMPU), tem por missão principal a defesa da ordem jurídica, do regime democrático e dos interesses sociais e individuais indisponíveis, especialmente no âmbito das relações de trabalho. Ora, teria razão o autor quanto a escolha do árbitro, que não foi realizada diretamente pela parte hipossuficiente, mas foi acordada pelos sindicatos da categoria, pois o $\S 3^{\circ}$ do art. 37 da Lei $\mathrm{n}^{\circ}$ 12.815/2013 expressamente prevê que os árbitros devem ser escolhidos de comum acordo entre as partes . No caso, o sindicato não poderia atuar como substituto processual da vontade da parte quando se elege árbitro. No entanto, apesar de os sindicatos não poderem escolher o árbitro em substituição à vontade das partes, o agravo não alcança provimento, diante do óbice estritamente processual . Isso porque a indicação de afronta ao art. $114, \S \S 1^{\circ}$ e $2^{\circ}$ da CF é impertinente com o caso dos autos, pois o referido dispositivo trata de negociação e dissídio coletivo e não de dissídio individual, que na hipótese vertente é regido especificamente pela legislação infraconstitucional. Com relação à divergência jurisprudencial, os arestos indicados tratam genericamente acerca da utilização da arbitragem para resolução de conflitos individuais no âmbito da Justiça do Trabalho, mas não trazem as peculiaridades dos autos, sendo inespecíficos, a teor da Súmula 296 do c. TST. Agravo conhecido e desprovido. (BRASIL. TST. Ag-AIRR-964-77.2013.5.02.0447, $3^{\text {a }}$ Turma, Relator Ministro Alexandre de Souza Agra Belmonte, DEJT 29/03/2019)

$\mathrm{Na}$ mesma esteira, embora tratando controvérsia envolvendo organismo internacional, que não se submete às regras trabalhistas, o acórdão seguinte reforça a tendência instaurada na jurisprudência trabalhista, acerca do procedimento em questão:

AGRAVO INTERNO EM AGRAVO DE INSTRUMENTO EM RECURSO DE REVISTA. IMUNIDADE DE JURISDIÇÃO. CLÁUSULA ARBITRAL ESTIPULADA NO CONTRATO. NECESSIDADE DE SUBMISSÃO À ARBITRAGEM . A despeito das razões expostas pela parte agravante, merece ser mantido o despacho que negou seguimento ao Recurso de Revista. De fato, os arestos colacionados, os quais afirmam que não haveria a imunidade de jurisdição dos organismos internacionais, está superada pela jurisprudência desta Corte, sendo aplicável o óbice da Súmula n. ${ }^{\circ} 333$, do TST. Ademais, há decisões anteriormente firmadas no âmbito desta Corte, em situações semelhantes à dos presentes autos, envolvendo os mesmos Reclamados, nas quais foi constatado que a cláusula arbitral estipulada entre as partes deve ser respeitada, sob pena de extinção do feito, sem julgamento de mérito, não havendo de se falar em violação dos artigos $5 .^{\circ}$, XXXV e LV, da Constituição Federal, e dos artigos $1 .^{\circ}$ e $8 .^{\circ}$, da Lei n. ${ }^{\circ} 9.307 / 1996$. Assim, deve ser mantida a decisão denegatória. Agravo conhecido e não provido. (BRASIL. Tribunal Superior do Trabalho. AgRg-AIRR-111-08.2004.5.10.0012, 1ª Turma, 
Relator Desembargador Convocado Roberto Nobrega de Almeida Filho, DEJT 05/11/2018).

Cobra relevo, também, a redação dos novos artigos 611-A e 611-B inseridos na CLT pela precitada reforma, os quais dispõem sobre matérias que podem ser tratadas em acordos ou convenções coletivas de trabalho, que autorizariam, reforçando o dispositivo central, a estipulação da arbitragem como procedimento para solução de conflitos trabalhistas, sem amortecimentos inconstitucionais.

Examinando a possibilidade, Daniel Gemignani e Tereza Aparecida Asta Gemignani, discorrem sobre a aplicabilidade da arbitragem nas ações de competência da Justiça do Trabalho:

\footnotetext{
Analisando os textos legais, vê-se que o legislador achou pertinente permitir que empregados individuais qualificados gozassem de maior autonomia negocial e adotassem a via arbitral como forma de solução de litígios. Ressalte-se que esse também parece ter sido o racional da tentativa de reforma da Lei de Arbitragem de 2015 no que concerne à arbitragem trabalhista, que, ao incluir a possibilidade de adoção por determinados trabalhadores, circunscreveu qual grupo teria esse direito. (GEMIGNANI; ASTA GEMIGNANI; 2018, p. 11)
}

Sob outro viés, a lei de arbitragem é clara que havendo vicio poderá a sentença arbitral ser anulada, não se impedindo o procedimento judicial tradicional para tal fim, inserindo mecanismo de segurança aos envolvidos.

Desse modo, garantir ao empregado a utilização do procedimento arbitral de modo célere e sem custos para os pobres, interfere diretamente na dignidade da pessoa humana na valorização do trabalho e na proteção integral ao trabalhador, eis que a maioria das lides trabalhistas envolve o pagamento de verbas alimentares. E quem tem fome, tem pressa.

\section{CONSIDERAÇÕES FINAIS}

Como restou comprovado, não há óbice, ao menos por ora, para adoção da arbitragem nos conflitos trabalhistas individuais, independente da remuneração envolvida, desde que atentem-se para os cuidados com a imparcialidade, a paridade de armas, a publicidade e a gratuidade do procedimento para os hipossuficientes.

Outra conclusão que se oferta é a de que o princípio da igualdade e a vedação de discriminem em decorrência da condição econômica impõe interpretação conforme ao artigo 
507-A, da CLT, para possibilitar a qualquer trabalhador adotar a arbitragem para dirimição de seus trabalhistas.

Esse mesmo princípio exige que se adote a arbitragem trabalhista gratuita, para não desassistir os obreiros pobres, garantindo-se-lhes, ainda, o aceso ao advogado ou á advogada, profissionais essenciais à distribuição de justiça como acesso ao sistema de direitos.

Por fim, em tempos de escalada das novas tecnologias comunicacionais, pode-se adotar a arbitragem por meio eletrônico, tal qual já se fez com o processo judicial, restando em aberto, para nova pesquisa, as indagações colocadas acerca da precarização do trabalho por meio das plataformas digitais.

\section{REFERENCIAS}

ALEGRETTI, Laís. Reforma trabalhista reduz processos e muda vida de advogados: 'Fonte secou'. Londres: BBC News Brasil, 08 jul. 2019. Online. Disponível em:

https://www.bbc.com/portuguese/brasil-48830450. Acesso em 28 ago. 2019.

AMARAL, Guilherme Rizzo. Arbitragem nos conflitos trabalhistas individuais. Revista Eletrônica CONJUR, de 23 jan. 2018. Online. Disponível em:

https://www.conjur.com.br/2018-jan-23/guilherme-amaral-arbitragem-conflitos-trabalhistasindividuais . Acesso em 28 ago. 2019.

ANDRADE, André Gustavo Corrêa. O princípio da dignidade humana e sua concretização judicial. Revista da EMERJ, v. 6, n. 23, 2003. Online. Disponível em:

http://www.emerj.tjrj.jus.br/revistaemerj_online/edicoes/revista23/revista23_316.pdf. Acesso em: 16. jul. 2019.

ASTA GEMIGNANI, Tereza Aparecida; GEMIGNANI, Daniel. A arbitragem no direito trabalhista: um desafio a ser enfrentado. Revista CEJ, Brasília, Ano XXII, n. 75, p. 7-17, maio-ago. 2018. Online. Disponível em:

http://www.jf.jus.br/ojs2/index.php/revcej/article/view/2391/2261. Acesso: 17 jul. 2019.

AYOUB, Luiz Roberto. A jurisdicionalidade da arbitragem. Revista da EMERJ, v. 4, n. 15, 2001.

BARROS, Alice Monteiro de. Curso de direito do trabalho. 10a ed. São Paulo: LTr, 2015.

BOBBIO. Norberto. Teoria do Ordenamento Jurídico. $6^{a}$ ed. Brasília: Editora Universidade de Brasília, 1995.

BOLZAN DE MORAIS, José Luiz. Mediação e Arbitragem: Alternativas a Jurisdição. Porto Alegre: Livraria do Advogado Editora, 2012. Edição do Kindle. . O Estado de direito "confrontado" pela "revolução da internet"!.

Revista Eletrônica do Curso de Direito da Universidade Federal de Santa Maria. V. 13, n. 3/2018, p. 881-882. 
BRASIL. Constituição da República Federativa do Brasil de 1988. Brasília, DF. Publicada no Diário Oficial da União de 05 out. 1988. Disponível em:

http://www.planalto.gov.br/ccivil_03/Constituicao/Constitu icao.htm. Acesso em: 16 jul. 2019.

BRASIL. Lei no 13.467, de 13 de julho de 2017. Altera a Consolidação das Leis do Trabalho (...). Presidência da República. Brasília, DF, publicada no Diário da União de 14 de julho de 2017. Online. Disponível em: https://www2.camara.leg.br/legin/fed/lei/2017/lei-13467-13julho-2017-785204-norma-pl.html.Acesso: 19 jul. 2019.

BRASIL. Lei no 9.307, de 23 de setembro de 1996. Dispõe sobre a arbitragem. Presidência da República. Brasília, DF, publicada no Diário Oficial da União de 24 de setembro de 1996. Online. Disponível em: http://www.planalto.gov.br/ccivil_03/leis/19307.htm. Acesso em 16 jul. 2019.

BRASIL. Lei $\mathrm{n}^{\circ}$ 8.078, de 11 de setembro de 1990. Dispõe sobre a proteção do consumidor e dá outras providências. Brasília, DF, publicada no Diário Oficial da União de 12 de setembro de 1990. Disponível em: http://www.planalto.gov.br/ccivil_03/leis/18078.htm Acesso em 27.jun.2019.

BRASIL. Decreto ${ }^{\circ}$ 591, de 06 de julho de 1992. Atos Internacionais. Pacto Internacional sobre Direitos Econômicos, Sociais e Culturais. Promulgação. Presidência da República. Publicado no Diário Oficial da União de 07 de julho de 1992. Online. Disponível em: http://www.planalto.gov.br/ccivil_03/decreto/1990-1994/d0591.htm. Acesso em: 16. jul.2019.

BRASIL. Supremo Tribunal Federal. Agravo Regimental na Sentença Estrangeira ${ }^{\circ}$ 5206-8. Relator Ministro Sepúlveda Pertence. Julgamento de 12/12/2001, publicado em Brasília, DF, no Diário da Justiça de 30/04/2004, p. 59. Online. Disponível em:

http://redir.stf.jus.br/paginadorpub/paginador.jsp?docTP=AC\&docID=345889 Acesso em 28 ago. 2019.

BRASIL. Supremo Tribunal Federal. Ação Direta de Inconstitucionalidade n ${ }^{\circ}$ 5766, Relator Ministro Luís Roberto Barroso. Partes Procuradoria Geral da República e Presidência da República. Online Disponível em: http://portal.stf.jus.br/processos/detalhe.asp?incidente=5250582.Acesso: 28 ago. 2019.

BRASIL. Tribunal Superior do Trabalho. Agravo Regimental no Agravo de Instrumento no Recurso de Revista n ${ }^{\circ}$ 964-77.2013.5.02.0447. $3^{\text {a }}$ Turma. Relator Ministro Alexandre de Souza Agra Belmonte. Brasília, DF, publicado no Diário Eletrônico da Justiça do Trabalho de 29 de março de 2019.

BRASIL. Tribunal Superior do Trabalho. Agravo Regimental no Agravo de Instrumento no Recurso de Revista ${ }^{\circ}$ 111-08.2004.5.10.0012. $1^{\text {a }}$ Turma. Desembargador Federal Convocado Roberto Nóbrega de Almeida Filho. Brasília, DF, publicado no Diário Eletrônico da Justiça do Trabalho de 05 de novembro de 2018.

CARMONA, Carlos Alberto. Árbitros e juízes: guerra ou paz? MARTINS, Pedro A. Batista et al. Aspectos fundamentais da lei de arbitragem. Rio de Janeiro: Forense, 1999.

DELGADO, Maurício Godinho. Curso de direito do trabalho. 14ª ed. São Paulo: LTr, 2015.

DONIZETTI, Elpídio; CERQUEIRA, Marcelo Malheiros. Curso de processo coletivo. São Paulo: Editora Atlas, 2010. 
ESPANHA. Decreto Real $n^{\circ}$ 231/2008. Madrid, 15 de fevereiro, publicado no BOE-A-2008357, de 25 de fevereiro de 2018. Online. Disponível em:

http://www.madrid.org/cs/Satellite?c=FRAME_Contenido_FA\&childpagename=PortalConsu midor\%2FFRAME_Contenido_FA\%2FPTCS_contenidoReportajes\&cid=1343066136568\&p $=1343064181510 \&$ pagename=PTCS_wrapper. Acesso em 29 ago. 2019.

LEAL, Rosemiro Pereira. Teoria Geral do Processo: primeiros estudos. $14^{\mathrm{a}}$ ed. Belo Horizonte: Fórum, 2018.

LEITE, Carlos Henrique Bezerra. Curso de Direito do Trabalho. $7^{\text {a }}$ ed. São Paulo: Saraiva, 2016.

OIT. Constituição da Organização Internacional do Trabalho e seu Anexo (Declaração de Filadélfia). Online. Disponível em:

http://www.oitbrasil.org.br/sites/default/files/topic/decent_work/doc/constituicao_oit_538.pdf . Acesso em: 18. jun.2019.

OIT. Oficina Internacional del Trabajo. Las plataformas digitales y el futuro del trabalho: Cómo fomentar el trabajo decente en el mundo digital. $1^{\text {a }}$ ed. Genebra: 2019.

ONU. Organização das Nações Unidas. Escritório do Alto Comissariado. Declaração Universal dos Direitos Humanos. Paris: 10 dez. 1948. Disponível em:

http://www.ohchr.org/EN/UDHR/Documents/UDHR_Translations/por.pdf. Acesso em: 16. jun. 2019.

STUCHI, Victor Hugo Nazário. A valorização do trabalho humano como forma de realização do ideal de justiça social. Revista Scientia FAER, Olimpia, Ano 2, Volume 2, $1^{\circ}$ semestre de 2018. Online. Disponível em:

http://uniesp.edu.br/sites/_biblioteca/revistas/20170802101122.pdf Acesso em: 17.jun.2019 